\title{
Surgical Skills Training For Robotic Assisted Surgery
}

\author{
Juan D. Hernandez R. ${ }^{1}$, Fernando Bello² and Ara Darzi² \\ ${ }^{1}$ Universidad de los Andes School of Medicine, \\ Imperial College London Faculty of Medicine \\ ${ }^{1}$ Colombia, 2 United Kingdom
}

\section{Introduction}

The enormous impact of technology in medicine has a remarkable example in the introduction of robotic systems in minimally invasive surgery approximately a decade ago. With relatively small modifications to the commercial systems originally introduced, the field of robotic surgery is now established and growing. Several thousand procedures have been practiced successfully in areas like general surgery, thoracic and cardiovascular surgery, urology, gynaecology, and others. Research in robotic surgery is growing exponentially, and its future is promising. The systems employed by the specialties mentioned above are known as telemanipulator systems due to their technical configuration and interaction with the surgeon. Although there are other robotic systems employed in, for example, orthopaedic and urologic surgery, this chapter will focus on the use of telemanipulator systems for laparoscopic or minimally invasive surgery, and that is what will be meant when using the expression robotic surgery

Possible limitations to massive use of surgical telemanipulator systems could be the cost, technical capabilities of hospitals around the world and surgical expertise and training. The aim of this chapter is to explore this last issue, which, in the end, will determine if these systems are widely accepted by the surgical community and its use is extended beyond hospitals and academic centres in the developed world. It will set up to find if surgeons require new abilities to practice surgical procedures using telemanipulator systems; if there is an advantage for already trained laparoscopic surgeons or if surgical trainees can easily learn the use of this equipment. It will also discuss if this technology has an impact on the learning curve of advanced laparoscopic procedures, and how scientists and surgeons are working to improve its performance.

\section{Ergonomic limitations of laparoscopic surgery (LS)}

Since the massive expansion and use of minimally invasive surgery (MIS) in the early 1990's shortly after its introduction, extensive evidence has demonstrated its advantages over open surgery in different procedures (McMahon et al, 1994; Williams et al, 1993; Z'graggen et al, 1998): Faster recovery and short hospital stay with less pain and fewer complications. These factors, together with good surgical results, have resulted in procedures such as laparoscopic cholecystectomy, Nissen's fundoplication and adrenalectomy becoming gold 
standard techniques for those surgeries (National Institutes of Health 1993, Heemskerk et al, 2007).

However, the swift developments of MIS after the first laparoscopic cholecystectomies were presented to the world (Ostrosky \& Jacobs, 2003; Muhe, 1992), led to the introduction of instruments and equipment by the industry, but little thought was spent in making them user friendly from an ergonomic point of view. They have been basically the long-shaft versions of the traditional instruments used in open surgery, many of them unchanged since the 19th century. As a result, surgeons may experience nerve compression with an area of paresthesia in the thumb (Kano et al, 1995), produced by the position of the finger in the instrument and the force or pressure applied to it.

MIS has some other ergonomic implications for the surgeon that make it very challenging, and for some surgeons difficult enough as to discourage them from learning advanced laparoscopic skills. In spite of that, authors consider laparoscopic surgery the best approach to a large number of procedures, at least until robotic surgery proves otherwise. However, there are characteristics of LS that could be improved through RS.

The drawbacks of MIS are several. First, long instruments placed through fixed entry points create a fulcrum effect, with the tip of the instrument moving in the opposite direction of the hands. This situation is made worse in obese patients ( $\mathrm{Yu}$ et al, 2006). In these cases, the reverse movement is summed to the high resistance of a very thick abdominal wall. Second, the surgical field is viewed on a 2-D screen often positioned on either side of the patient, not where the actual surgical field really is. Additionally, the camera acting as the surgeon's eyes is held by an assistant, who may not have full knowledge of the procedure, or may get distracted or tired. All these elements create an unnatural environment where the surgeon has lost orientation, the eye-hand-target axis and visual depth perception (Falk et al, 1999; Smith et al, 2001). Finally, the surgeon is no longer in direct contact with tissues, but through an instrument that drastically reduces its tactile perception. This is due to its length and the fact that the instrument's shaft goes trough a port that creates friction.

Other problems appear by uncomfortable and sometimes awkward positions assumed during long procedures, producing pain and muscular fatigue of the back, shoulders, elbows and wrists (Galleano et al, 2006). Other appliances often cause discomfort, for example, foot pedals for instruments that use energy. There is not only physical but mental fatigue and strain, attributed to the effort of adapting to 2-D vision (Byrn et al, 2007). These working conditions may not only have long term effects on surgeon's health, but also affect performance in terms of time and outcomes.

As none of the abovementioned conditions are present in open surgery, or for that matter, in any usual daily activity humans have learned to do, they reduce the surgeon's normal dexterity and limit his ability to deal with difficult situations (Cadière et al, 2001). MIS procedures in confined spaces such as pelvis and retroperitoneum, but particularly in the thoracic cavity, are extremely difficult, and in some cases, simply impossible to complete. This is especially true if they include manoeuvres like suturing, which requires movements in different angles, including a 180 degrees action, which would be parallel to the shaft of the instrument (Bann et al, 2003).

A long learning curve has been the only existing path to overcome these difficulties (Smith et al, 2001), and many surgeons have failed to make the transition from open to MIS even in their area of expertise, since laparoscopic surgery requires a whole new set of skills many are not willing to learn. 


\section{MIS Skills acquisition and learning curve development}

The term "learning curve" is now an obliged element in medical publications, especially in the surgical field. It is used in reference to the process of gaining knowledge and improving skills in performing a specific procedure (Ramsay et al, 2000). It could be concluded that at some point a surgeon should reach a plateau. If the surgeon practices the same procedure frequently, he should keep a flat line, with occasional peaks and valleys which are normal to human performance.

Several authors have published learning curves of different surgical procedures based on their results through time. Outcomes like surgical time, mortality, morbidity, in-hospital stay, etc. have been used to establish the improvement of a group or an independent surgeon in performing a specific operation or technique (Watson et al, 1996). Advanced MIS has not been embraced by all surgeons as would be expected considering its advantages. This could be attributed to the important effort that needs to be invested in order to overcome long learning curves for most procedures (Yu et al, 2006).

In a systematic review, Ramsay et al comment that using outcomes like patients survival or complications, and quality assurance aspects like time to complete the surgical procedure and hospital stay as "proxies of learning" is inappropriate, since they are too general and do not provide accurate or objective definition of learning (Ramsay et al, 2000; Watson et al, 1996; Darzi et al, 1999).

The learning curve assessment should be based on factors more closely related to the surgeon's skills rather than in variables that are either too general, too difficult to control or not a direct reflection of learning. These measurements should be both quantitative and qualitative to capture a wide array of human learning manifestations, and ideally should have numerical representation to actually depict them as a curve. Examples of more appropriate parameters to objectively measure learning and improvement in surgical skills are number of movements, path length, time, number of errors. Such variables are reproducible and easily compared in different studies or when comparing LS and RS.

The reason these parameters have been considered useful to measure surgeons' learning curves is because an experienced surgeon practicing either a specific task or a whole surgical procedure performs a smaller number of movements and he is more precise, therefore having a shorter path length for the instruments and spending less time than a novice. As the surgeon or student in training practices, these variables resemble more and more those of the expert, and a learning curve can be defined.

At the authors institution (St Mary's Hospital), the parameters number of movements, path length and time spent, have been calculated in open and laparoscopic surgery on bench models. This is known as motion tracking analysis, and for the purpose of these measurements, the ICSAD (Imperial College Surgical Assessment Device) was developed. ICSAD uses an electromagnetic field to track the hand coordinates and to analyse objective measures for the assessment of surgical skills (Datta et al, 2001). The same concept has been applied to the assessment of robotic surgical skills using the Da Vinci telemanipulator system and ROVIMAS (Robotic Video \& Motion Analysis Software) (Dosis et al, 2003), bespoke software offering advanced motion and video analysis capabilities for open, laparoscopic and robotic surgical skills assessment. ROVIMAS can calculate and display the hand kinematics, the time, the total path length of hands, the number of movements made, the hand directions, velocities etc. It also synchronises these hand kinematics with simultaneously recorded procedural video. 


\section{RS Skills acquisition and learning curve development}

Contrary to the general perception of robots, surgical robots are not independent in their actions; they cannot move on their own and only respond to human direct commands. Current existing robotic systems used in general surgery (MIS) are known as master-slave telemanipulator systems. Commercially available FDA-approved systems are the Zeus System (Computer Motion, Inc., Goleta, CA) and the da Vinci ${ }^{\mathrm{TM}}$ Surgical System (Intuitive Surgical, Sunnyvale, California). Since Computer Motion was taken over by Intuitive Surgical, the only widespread commercial master-slave telemanipulator currently being sold and updated is the da Vinci system, and therefore will be the focus of this paper.

The da Vinci system is composed of a console where the surgeon sits (master), rests his arms and grabs the instruments controls; a computer interface where surgeon movements are transmitted to the instruments; a patient-side cart holding up to 4 robotic arms (slave) and a video cart consisting of the standard laparoscopic monitor, Xenon lights, insufflation equipment and video processing system. The robotic arms hold the camera and up to three instruments, two for surgeon's left and right hands, and the other to assist the surgeon. The workstation allows the surgeon to setup the system at the beginning of the surgery, to change the camera position and focus, and adjust the distance and position of the controls. It also has diathermy function pedals. To activate the controls, the surgeons forehead must remain at the headrest allowing him to comfortable see through the vision device, a binocular viewer that projects the images from a dual-lens scope with independent light sources and cameras for each eye. The images obtained are therefore in real time and threedimensional. The computerized interface is able to filter and scale surgeon movements, avoiding natural tremor and allowing the intuitive, natural hand movements to be reproduced in the small surgical field at an appropriate scale.

During the rapid introduction of MIS, higher incidence of common bile duct injuries in laparoscopic as compared to open cholecystectomy were recorded (Deziel et al, 1993, Shea et al, 1996; Z'graggen et al, 1998). These lesions are found more frequently in the initial cases of a number of surgeons. It is possible that these surgeons did not appreciate the unique skills required to practice laparoscopic surgery competently, leading to this situation. As mentioned before, some technically demanding tasks cannot be done safely or accurately enough using conventional laparoscopic instruments (Damiano et al, 2000; Loulmet et al, 1999), for example coronary artery bypass grafting in the confined spaces of the thorax. It is with this background that telemanipulators appear in laparoscopic surgery.

The feasibility of carrying out different surgical procedures with robotic systems has been demonstrated in different fields (Cadière et al, 1999; Chitwood et al, 2001; Falcone et al, 2000), with special emphasis in cardiac surgery (Falk et al, 1999) using both the Zeus and the da Vinci, with more than 2000 procedures performed just two years after their introduction (Ruurda et al, 2002), and a calculated 20,000 by the end of 2004 (Mehrabi et al, 2006). Both Zeus (no longer in production) and da Vinci have similar characteristics in their final forms: a set of robotic arms holding the camera and instruments, 3D visualization of the surgical field and instruments with "wrists" in their tips that allow complex movements in confined spaces, giving surgeons seven degrees of freedom instead of the four available in MIS (Bann et al, 2003; Falk et al, 1999).

Several authors have tested the advantages of the da Vinci ${ }^{\mathrm{TM}}$ Surgical System in clinical practice in a large number of surgical procedures (Cichon et al, 2000; Loulmet et al, 1999; Munz et al, 2003a; Heemskerk et al, 2007), and it has been reported that it allows surgeons to perform more complex tasks restoring surgical dexterity, hand-eye alignment and depth 
perception (Falk et al, 2001; Byrn et al 2007). When the surgeon sits at the workstation, it recreates the eye-hand motor axis that is lost in MIS (Ban et al, 2003), giving the surgeon the impression that when he moves his hands, the instruments move right in front of his eyes with similar degrees of freedom, mimicking his movements on the handles. Due to the position of the head in the viewing device, he feels immersed in the surgical field. It is in delicate and complex procedures, like cardiac surgery, where the virtues of the system are more evident. Tremor is eliminated through bandwidth filtering and there is improved visualization with the availability of three-dimensional viewing directly controlled by the surgeon. All these, combined with improved ergonomics for the operating surgeon in the seated position at the console, make clear advantages over the laparoscopic surgery setting (Bann et al, 2003). However, it remains to be proven if these advantages have an impact on patients outcomes. There are important setbacks in telemanipulators that also need evaluation and the establishment of strategies to deal with these obstacles. Very importantly, the surgeon has no direct tissue tactile feedback whatsoever, and therefore he has to trust only what he sees (Munz et al, 2004) and in visual cues that experience give when dealing with tissues and suture materials. Having no sense of tension, pressure or grasp on tissues and sutures increases the probability of a wide array of lesions or errors during tasks and surgical procedures for which a learning process is needed. It is therefore an important consideration when comparing LS and RS to keep in mind that there is a learning curve to a safe and accurate use of the robotic telemanipulator. An additional point to bear in mind is that, no matter how intuitive and user-friendly a telemanipulator system might be, it is still a tool, and therefore the operator needs to know the task or procedure beforehand if the system's usefulness is to be evaluated.

In order to avoid the problems that occurred with the introduction of laparoscopic surgery, (Scott et al, 2001; Shea et al, 1996; Watson et al, 1996) appropriate training and assessment need to be established for this new technology to ensure good outcomes. It is important therefore, that both the impact on the learning curve and any possible advantages over the standard laparoscopic technique be recognized, tested and objectively measured. Only using this approach its widespread use by the surgical community would be justified and supported.

\subsection{Learning robotic surgery skills}

Learning the basic use of the da Vinci system is very intuitive. Once a surgeon sits on the console, holds the controls and looks through the vision device, is perfectly able to move the instruments and practice simple tasks from the onset. They could reproduce the movements they typically do in open surgery. On the other hand, the main disadvantage is the total lack of tactile feedback. It forces the surgeon to trust only in his vision (3-D). It should be pointed out that in papers where subjects with no surgical experience are tested doing surgical tasks, they may not only be learning to use the robot, but learning the surgical task itself. Therefore, comparisons need to control for these variables in order to be valid. Such studies show advantages and disadvantages of the use of robots in surgery, better defining the systems current and future role. We now review some of the published studies. These were chosen from different specialties for their relevance in skill acquisition, attention to learning curves, number of cases and design.

Obek (Obek et al, 2005), published a study where twenty students with no knowledge of laparoscopic surgery where divided in two groups to determine if there was transfer of skills between robotic and laparoscopic surgery. After observing knot tying on the da Vinci with and without previous training in LS, they concluded that there is reciprocal transfer of skills between LS ad RS, although it is incomplete. They considered that training with LS previously 
is better than training with RS alone. Interesting findings were that novices learning intracorporeal suturing with the robot were faster and more precise than those learning with conventional laparoscopic instruments. As their attention was focused on skills transfer, they found that those who learned with LS did better in their last tasks on the da Vinci.

Heemskerk, in a study with medical students (Heemskerk et al, 2007), compared the skill acquisition in robotic and traditional laparoscopy. Subjects were randomized to start with RS or LS on three rather simple tasks and on knot tying as the fourth task. Researchers found that a steeper learning curve was achieved with LS, but RS allowed a faster and more accurate performance. Comparing with other studies, they suggested that the tendency to a flat learning curve in RS would be explained by a better performance from the start with RS, leaving little room for improvement. They also comment that RS may be more beneficial to surgeons with little or no experience in LS, and that benefit of robotic assistance would be more evident in complex surgical procedures.

Mehrabi et al designed a set of four training tasks for subjects with different surgical experience (Mehrabi et al, 2006). They were asked to practice four procedures in a pig, and then practice each of them in rats. After the training, they had to repeat all four procedures in a pig. They were able to demonstrate a learning curve and a significant improvement in quantitative and qualitative scores similar to all participants. They mention that learning process was independent of the subject's confidence on the surgical technique, and considered the learning process closer to open rather than to laparoscopic surgery. They recommend that every surgeon should go through an animal model training course before clinically using the da Vinci system. Ruurda published the initial experience of the Utrecht group with 208 different procedures (Ruurda et al, 2005). They practiced a variety of procedures with a small number of complications and results at least as good as with laparoscopic surgery. Setup time and positioning of the robot were improved as they practiced different surgical interventions, of different degrees of complexity. They conclude that the application of the current generation of telemanipulators should be reserved to procedures with complex dissection and suturing, and that future systems will need to reduce their size, complexity and cost.

An exceptional example of a complex MIS procedure is the Roux-en-Y gastric bypass for morbid obesity. Multiple bowel anastomoses and a major rearrangement of the gastrointestinal tract make it a great challenge. Mechanical sutures help reduce the burden of intracorporeal suturing, but even so, the learning curve is long and steep. Describing a teaching environment for RS, Ali (Ali et al, 2007) trained an MIS fellow in RS, making the experience progressive in complexity. He found that the fellow's performance exceeded the senior members of the team during their own learning curve. In this study, the team opted for a hand-sewn anastomosis, which greatly raises the difficulty. During his clinical practice, the fellow had no complications originated on technical errors. This group considered possible to reduce the learning curve of a complex surgical procedure using the telemanipulator system within an organized training program. Yu et al reported the learning curve for 100 cases (Yu et al, 2006). They found that every twenty patients operating time was reduced, and on the last twenty patients was less than average. Another significant finding was that they had no leaks and no deaths and a smaller rate of strictures than other series. The $0 \%$ leak rate is important since other series have reported $7 \%$. They suggested the use of the da Vinci to train surgeons and help them overcome the learning curve.

This evidence shows that learning to use the robot requires a short exposure to the system as compared to laparoscopic surgery, and may have its main impact on complex procedures and in the performance of surgeons with no experience in LS. 


\subsection{Learning curve and differences in RS performance according to LS surgical expertise}

An issue that has become of great importance in RS is that of the performance of subjects with different degrees of knowledge and experience in LS. A number of authors have explored this issue with different approaches. Zorn followed the learning curve of an experienced laparoscopic surgeon starting his practice of robotic radical prostatectomy (Zorn et al, 2007). He found that the results and learning curve were similar to a group of urologists who switched to RS, and whose previous experience was only in open surgery and not in LS. In other words, Zorn's study suggest that laparoscopic experience is not a requirement to practice RS proficiently, and that surgeons with expertise in an open surgical technique will perform as good as laparoscopic surgeons practicing RS, both during the learning curve and when reaching the plateau.

Munz et al presented a bench model experiment of cardiac surgery, in which a left internal mammary artery was anastomosed to the left anterior descending artery of the heart (Munz et al 2003b). The procedure was repeated five times by expert cardiac surgeons, and then compared to the open approach by the same subjects. Qualitative analysis of video recordings and quantitative motion tracking analysis with ROVIMAS (da Vinci) and ICSAD (open surgery) showed an important improvement in performance represented by time taken, number of movements, path length, circumference to area ratio and overall performance for robotic surgery. Although it is not mentioned in the paper, the cardiac surgeons taking part in this study were not experienced in minimal access cardiac surgery. In a related paper, another British team established a progressive programme to introduce robotic cardiac surgery (Trimlett et al, 2003). They started with pig hearts, then live animals and finally went into clinical practice. In the process, they found that the learning curve is short and can be reproduced when comparing different subjects and that moving to clinical practice is rapidly achievable.

On another St. Mary's group experiment (Hernandez et al, 2004), 13 surgeons naïve to the telemanipulator system were divided in two groups and their learning curves on a bench model experiment were followed. One group was formed by experienced laparoscopic surgeons and the other by surgeons and surgical registrars without laparoscopic experience. The model was composed of two segments of synthetic small bowel assembled in a jig and fixed in a standardized position in a closed box. Surgeons had to complete an anastomosis with interrupted stitches in a single layer. The bowel anastomosis model was chosen because it simulates a complex procedure that requires forward planning and the use of a significant range of skills, and entails a longer learning process. It should resemble the practice of a complex surgical procedure, which is the real purpose of the robot. Results showed clearly an improvement for every subject in all variables measured (time and motion tracking analysis and quality of performance), which clearly depicted a learning curve in just five repetitions of the task (Fig. 1). A surprising finding was that between the two groups there was not a significant difference at the final task in any of the measurements. In other words, by the end of the experiment an after only five procedures completed using the da Vinci system, novice surgeons performed as well as the experienced laparoscopic surgeons. It is worth underlining that some of the trainees had to be taught how to do intracorporeal knot-tying from scratch. 


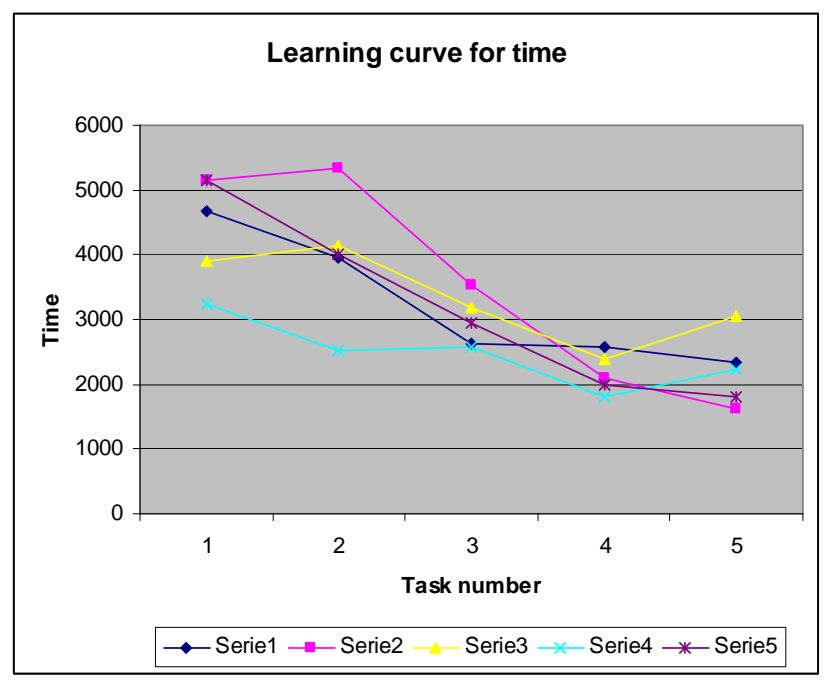

a)

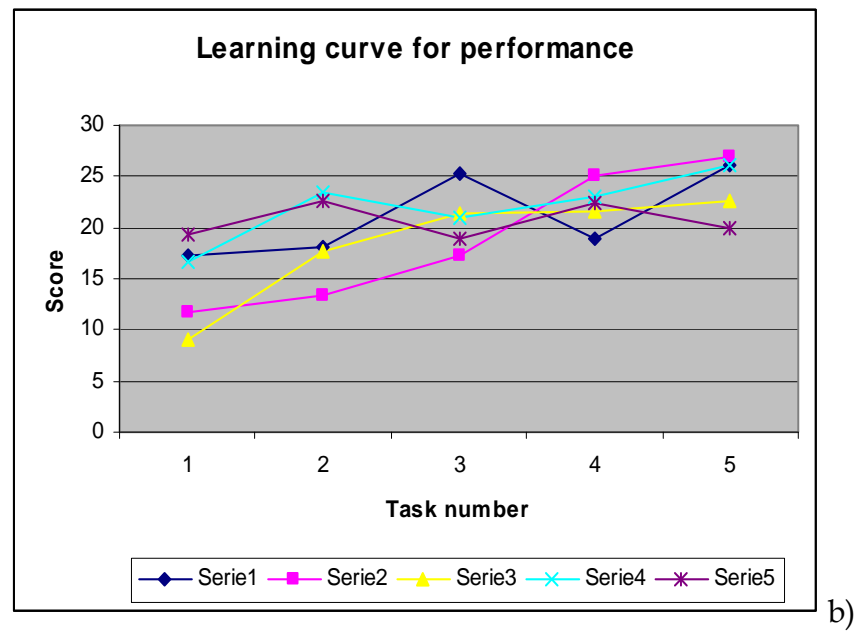

Figure 1. Graphics representing the learning curves for five subjects from both groups for time (a) and for quality of performance (b). Same color lines in a) and b) represent one surgeon

Closer examination of the curves shown in Fig. 1 reveals that there are differences in learning from one surgeon to another. For example, surgeon represented as series 2 (pink line/squares) showed a rapid and clear progress in the learning curve with the most important reduction in time of the study and a marked improvement in the score achieved. Series 1 (blue line/diamond) had an important improvement in time taken to complete the five tasks, but in terms of quality had a very uneven performance, with the third task scored as good as the fifth, but with a poor score for the fourth. Series 5 (Purple line, stars) had a steep reduction in time but an almost flat line for score. In spite of the differences, every single surgeon had a better time and score when comparing first and 
last task, and it was possible to draw a learning curve for each of them. This is an important achievement for a complex task in just five repetitions. It is the authors' opinion that this performance was possible due to the special characteristics of the da Vinci system.

In a clinical study of robot-assisted laparoscopic aorto-iliac bypasses (Diks et al, 2007), the authors showed a clear improvement after the eighth of seventeen patients. The learning curve was shorter when compared with other studies, since the aortic clamp time and aortic anastomosis time were significantly reduced. It remained a long and very complex procedure even with robotic assistance.

Based on these studies, it is then possible to say that the learning curve for complex tasks on the da Vinci system is shorter than expected as compared to LS, and that there may not be a difference between experienced and non-experienced surgeons. This seems to be truth only after the non-experienced surgeons have learned the procedure itself, a fact that constitutes a variable in the first tasks. These studies also seem to show that results are more favorable to robotic use when the task or surgical procedure complexity is higher.

\subsection{Comparison in clinical practice of LS and RS}

Several studies have compared laparoscopic and robotic surgery in specific procedures, especially in urologic surgery.

In an interesting study, Link et al compared robotic and laparoscopic pyeloplasty (Link et al, 2006). Laparoscopic pyeloplasty is a complex procedure because extensive, precise suturing is necessary, and therefore advanced skills are a requirement. The authors compared 10 procedures practiced with the da Vinci system by an urologist expert in laparoscopic surgery and ten laparoscopic pyeloplasties by the same surgeon. They found that time, complications and quality of the procedure were comparable, rendering the robotic assistance unnecessary for experienced laparoscopic surgeons. Additionally, cost was clearly higher in RS. In their conclusion they consider the system would be useful to surgeons without training in laparoscopic intracorporeal suturing.

Following the same line, El Nakadi et al compared robotic and laparoscopic Nissen's fundoplication in a randomized controlled trial (El Nakadi et al, 2006). They followed 20 patients randomized in two groups, evaluating complications during a one-year period. Operative time was longer with the robot, and there was no difference in complications and postoperative symptoms. Costs were several times higher with RS. The authors consider there is no advantage in using the robot for Nissen's, and numbered as disadvantages of the system the lack of appropriate instruments, high costs and longer setup times.

In another Nissen's study, Draaisma (Draaisma et al, 2006) found no differences in operating time, quality of life, oesophageal manometry and $\mathrm{pH}$ monitoring and symptoms. They found that surgeons comfort and visualization had an important improvement, but they conclude that the use of the da Vinci for the Nissen fundoplication is not justified.

The use of telemanipulators by expert surgeons in less demanding procedures does not seem to bring any particular advantage. The explanation could be that expert surgeons use visual cues and references that allow them to practice even complex procedures accurately, safely and in short times. Therefore, they seem to have successfully overcome the limitations of LS addressed by RS and, consequently, robot assistance does not appear to be useful for them. 


\section{Technological developments that enhance RS performance and safety}

When using a telemanipulator system, the surgeon has to relay only in what he is seeing, since he is not having any physical contact with the patient when sitting at the console, and therefore he cannot count on the partial feedback that exists in MIS. It has been proved that 3-D vision enhances surgical performance and reduces errors (Munz et al, 2004). Additionally, motion scaling, tremor abolition and instruments with "wrists" improve performance by $50 \%$, and when 3-D vision is added, time spent is reduced by $20 \%$ and dexterity is enhanced by 15\% (Moorthy et al, 2004). However, there are additional technical features that could improve the performance of robotic surgery even more, making the experience more realistic and immersive.

There is ongoing investigation to improve the surgeon's performance in robotic surgery and to bring additional technical capabilities in order to perform surgical procedures more safely and accurately.

\subsection{Motion tracking}

Following the successful application of motion analysis using the ICSAD, the same concept has been applied to the assessment of robotic surgical skills using the Da Vinci telemanipulator system. The ROVIMAS software (Dosis et al, 2003) can calculate and display all the variables of motion tracking analysis and is able to provide facilities such as a video player synchronized with the hand kinematics. The latter enables the comprehensive assessment of surgical skills, since every task can be watched through the video with simultaneous real-time displays of dexterity measures (Dosis et al, 2004).

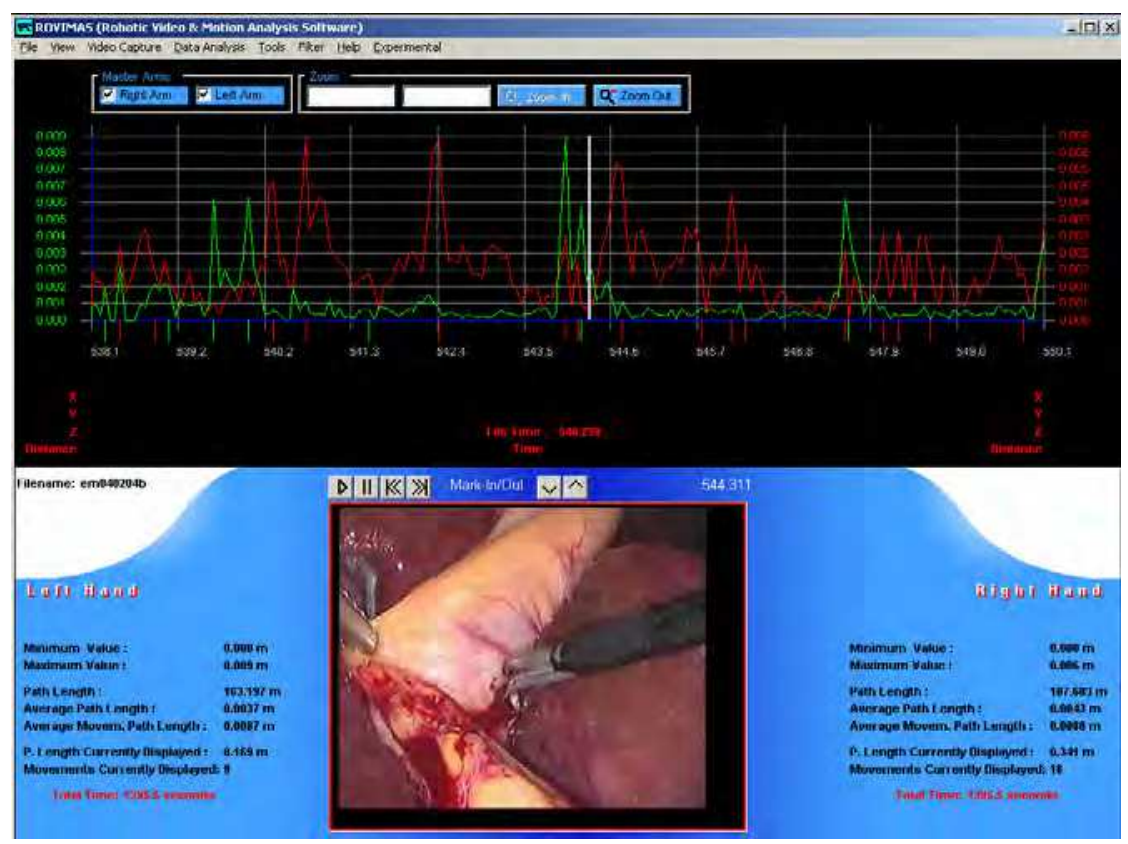

Figure 2. Sample screen image of surgical video synchronized with motion analysis graphics and data. Published with authorization of the Revista Colombiana de Cirugía 
The analysis of real-time kinematic data coming from the master arms holding the instruments and streamed from the computer interface of the da Vinci system displays distance and velocity graphics calculated from the robotic positional data. It can also analyse and produce graphics on trajectory, give statistical results and allows zoomingin to observe specific movement patterns. The use of ROVIMAS on the da Vinci and the ICSAD on laparoscopic and open surgery make an accurate comparison between the three surgical approaches possible, reducing methodological bias. Some of the studies carried out at the Imperial College London and included in this chapter have used this technology.

Figure 2 represents the layout of a computer screen showing the ROVIMAS data. This data may be specific for left and right hand, can show time taken, path travelled by instrument tips and number of movements. In the example, the observer could zoom-in at a graphic's segment and review specific movements, and compare those movements with the synchronized image to check for errors or very small movements. In that sense, the assessors will instantly know when, why and in which part of the procedure the surgeon manipulated with higher hand velocity (for example, when dealing with a bleeding situation).

The purpose of this project has been to research and enhance the motion analysis system with stochastic models to discriminate levels of expertise in real and complex procedures. Hidden Markov Models are widely used for this purpose in speech, hand and other pattern recognition research areas and it is currently used in this project to recognize different steps in a procedure, different levels of expertise and to model surgical movements.

Dosis published a clinical experience of the use of ROVIMAS (Dosis et al, 2005). They recorded ten laparoscopic cholecystectomies practiced by five surgeons with different levels of training, in gallbladders with different degrees of difficulty. ROVIMAS allowed authors to discriminate expert from novice surgeons and also to demonstrate that the system can be used in an operating theatre without interfering with the procedure.

Apart from obtaining individual learning curves, these data could be used in the assessment of surgical performance of trainees or for surgeon's certification; to create simulations based in experts' performances or to compare novices to experts and this way setting minimum standards in robotic training, both in simulated or clinical settings. These aspects will have great impact in skill assessment and RS training.

\subsection{Augmented reality provision for robotic minimally invasive surgery.}

Augmented reality combines synthetic objects with the real world, in real-time. The presence of augmented reality will enable the surgeon to perceive, in real-time, supplementary information intra-operatively without turning away from the operating scene. In one of the possible scenarios, 3D models will be reconstructed from a patient's pre-operative CT/MRI scans and integrated with the intra-operative endoscopic video stream (Wang et al, 2004).

Several issues need to be addressed when producing augmented reality facilities: calibration, registration and tracking. Calibration determines the properties of the camera being used to view the operating field. These properties are required when creating the simulated scene. The next stage of the process is to accurately align the 
virtual objects with their counterparts within the video sequences. This matching of real and virtual is known as registration. Once this blending has occurred, the dynamics of the surgical scene must be taken into account. Any deformation of structures, especially those due to tissue-tool interactions, need to be tracked. The virtual objects can then be updated accordingly and re-rendered onto the display (Wang et al, 2006).

It is hoped that by providing augmented reality facilities to the da Vinci surgical system, the enhanced visualization will allow for robotic image guided surgery. It will also advance the education of trainee surgeons by allowing them to carry out simulated robotic procedures with the aid of these extra capabilities.

A form of augmented reality would actually give surgeons back part of the sensory information lost partially in LS and completely in RS. Force and tactile feedback would require adapting sensors to the tips of the instruments. This would let the surgeon know if he is applying to much pressure or traction to a tissue or suture material. For example, to introduce the needle in a coronary artery during cardiac surgery requires feeling the tissue being pierced by the needle, then carefully passing the suture trough it and delicately tying a knot with the application of the right amount of pressure (Okamura AM, 2004).

An elegant experiment by a team from Johns Hopkins (Akinbiyi et al, 2006.) has combined a tracking system attached to the instruments of the da Vinci system with an augmented reality array based on haptic feedback. The variation is that instead of sending haptic feedback directly to the surgeon's hands, they used what is called sensory substitution. The force surgeon is applying to tissue is graphically represented and overlaid on the streaming video from the camera that the surgeon is viewing on the visor device of the console. They were able to demonstrate that using the force feedback with sensory substitution, forces were applied consistently, there were fewer errors and not one suture was broken due to excessive traction, and knots were tied accurately.

In a series of experiments, Reiley was able to prove that the use of visual force feedback produced lower suture breakage rates, in expert and novice robotic surgeons and in subjects with no surgical training (Reiley CE, 2007). She suggested that the use of these aides would reduce novice surgeons' learning curves.

Finally, a method called active constraint or haptic visual fixtures creates limits for the movement of the instruments within or outside certain boundaries. Dedicated to minimally invasive surgery in the heart, two types of active constraint were developed by Borelli et al at Imperial College London: the inner and the outer regions. The aim of "active constraints" in the inner-regions is to constrain the cutting tool inside the boundary of a desired area, while in the outer-regions the entry of the cutting tool is prevented within the central delimited area. In both cases there is an intermediary third region, modelled by a spring and damper, which allows the cutting tool to transition from the allowed to the forbidden region, without causing instability [Borelli et al, 2003].

All these future supporting tools should improve surgeons' performance on the system, especially for those who are in training, but will also make procedures safer reducing the chance for human error.

\section{Telerobotics, telementoring and telesurgery}

Tele-surgical procedures have been practiced using satellite links between Europe and the US and Asia and the US (Chitwood et al, 2001; Smith et al, 2001), and some of them 
via terrestrial fiberoptic networks (Marescaux et al, 2002). In a master-slave telemanipulator system setup, the surgeon does not need to be by the patient; furthermore, the system allows the surgeon not only to be remote from the slave, but also from the operating room (Cadiere et al, 1999). This has important implications for training surgeons in new procedures (Bann et al, 2003) and for space program or military use, but will require high-speed linkups via telephone or satellite (Lee et al, 1998; Fabrizio et al, 2000; Marescaux et al, 2002). Fabrizio (Fabrizio et al, 2000) have examined the effect of time delay that occurs with telemonitoring: programmed incremental time delays were made in audiovisual acquisition and robotic controls. They concluded a time delay of less than $700 \mathrm{~ms}$ was acceptable. Above this time the number of errors increased; although the general consensus suggests shorter times -300 ms (Marescaux et al, 2001; Marescaux et al, 2002).

To study the effect of time delay as it would present in telesurgery, Thompson designed a laboratory-based experiment using laparoscopic tasks (Thompson et al, 1999). They were able to show that video time delays significantly affected performance, and that this effect was magnified when haptic devices were also affected by the time delay.

Interest in telesurgery remains, but it is dampened by the lack of appropriate, widely available technology that will reduce the time delay of video and audio signals transmission. The potential for use in remote areas including the battlefield and space are enormous. It has to be kept in mind however, that for the currently available systems, there must be a laparoscopic trained surgeon by the side of the robotic arms cart, and therefore, at the patient side. The reason is that the port placement selection and introduction are done by him, not by the system alone. This is an obstacle to remote surgery that would have to be addressed with future systems or through specialized personnel training.

\section{Conclusions}

Robotic surgery using telemanipulator systems has been proved to be feasible and safe in several tens of thousands of procedures carried out around the world. It has demonstrated its utility in complex procedures in vascular, urological and bariatric surgery, amongst other specialties. As a matter of fact, a totally laparoscopic coronary artery bypass is not feasible without the robot. However, current evidence does not favour the widespread use of telemanipulators in general surgery, since the time and outcomes do not differ from laparoscopic surgery, and costs are excessively high. Another factor against is the current size and design of the system. Da Vinci's robotic arms are large and cumbersome, making setup times prolong surgeries.

It can be suggested that comparative studies between LS and RS have been conducted with expert laparoscopic surgeons, which would have two effects. First, laparoscopic performance for these subjects is excellent, since they have overcame the difficulties LS places to novice surgeons, therefore, the experts do not feel a great difference between both environments. Second, as they are experts, the learning curve in RS will tend to be flat, making any difference non-significant.

In spite of these difficulties, it is good to keep in mind that we are seeing just the first generation of commercial surgical telemanipulators, and is possible to think that they could follow a similar path in development as personal computers and cellular telephones, of course in a different proportion. 
Several authors support the theory that robotic surgery's greatest impact in performance will be found in trainees or in surgeons with no laparoscopic experience. These surgeons will go through learning curves that are shorter than the ones they would have learning the same procedure laparoscopically. As most surgeons in the world only perform cholecystectomy through a laparoscopic approach, the potential population is very numerous. The challenge of this technology is to attract them by improving the aforementioned problems.

The future success of robotic surgery largely depends on new generation of telemanipulator systems that should be cheaper, smaller in size, easy to use and with a wide range of instruments and functions.

\section{References}

Akinbiyi T, Reiley CE, Saha S, Burschka D, Hasser CJ, Yuh DD, Okamura A (2006). Dynamic augmented reality for sensory substitution in robot-assisted surgical systems. 28th IEEE EMBS Annual International Conference, Conference Proceedings pp. 567-570.

Ali MR, Rasmussen J, BhaskerRao B (2006). Teaching robotic surgery: a stepwise approach. Surg Endosc, 21: 912-915.

Bann S, Khan M, Hernández JD, Munz Y, Moorthy K, Datta V, Rockall T, Darzi A(2003). Robotics in surgery. J Am Coll Surg, 196(5): 784-795.

Borelli J, Bello F, Rodriguez y Bena F, Davies B (2003). An active constraint environment for minimally invasive Heart Surgery: early experience of a cutting operation. Procs. Medicine Meets Virtual Reality 12, IOS Press, ISSN: 0926-9630

Byrn JC, Schluender S, Divino CM, Conrad J, Gurland B, Shlasko E, Szold A (2007). Three-dimensional imaging improves surgical performance for both novice and experienced operators using the da Vinci robotic system. Am J Surg, 193: 519522.

Cadiere GB, Himpens J, Vertruyen M, Favretti F (1999) The world's first obesity surgery performed by a surgeon at a distance. Obes Surg 9: 206-209

Cadiere GB, Himpens J, Germay O, Izizaw R, Degueldre M, Vandromme J, Capelluto E, Bruyns J (2001) Feasibility of robotic laparoscopic surgery: 146 cases. World J Surg 25: 1467-1477.

Chitwood RW, Nifong LW, Chapman WHH, Felger JE, Bailey BM, Ballint T, Mendleson KG, Kim VB, Young JA, Albrecht RA (2001) Robotic surgical training in an academic institution. Ann Surg 234: 475-486.

Cichon R, Kappert U, Schneider J, Schramm I, Gulielmos V, Tugtekin SM, Schuler S (2000) Robotic-enhanced arterial revascularization for multivessel coronary artery disease. Ann Thorac Surg 70: 1060-1062

Damiano RJ, Ehrman WJ, Ducko CT, Tabaie HA, Stephenson ER, Kingsley CP, Chambers CE (2000) Initial United States clinical trial of robotically assisted endoscopic coronary artery bypass grafting. J Thorac Cardiovasc Surg 119: 77827 ,

Darzi A, Smith S, Taffinder N (1999) Assessing operative skills. BMJ 318: 887-888.

Datta VK, Mackay SM, Mandalia M, Darzi AW (2001). The use of electromagnetic motion tracking analysis to objectively measure open surgical skill in the laboratory-based model. J Am Coll Surg, 193: 479-485. 
Deziel DJ, Millikan KW, Economou SG, Doolas A, Ko ST, Airan M (1993). Complications of laparoscopic cholecystectomy: a national survey of 4,292 hospitals and an analysis of 77,604 cases. Am J Surg, 165: 9-14.

Diks J, Nio J, Jongkind V, Cuesta MA, Rauwerda JA, Wisselink W (2007). Robot-assisted laparoscopic surgery of the infrarenal aorta, the early learning curve. Surg Endosc, March 1. Epub ahead of print. PMID: 17332959.

Dosis A, Bello F, Rockall T, Munz Y, Moorthy K, Martin S, Darzi A (2003). ROVIMAS: A software package for assessing surgical skills using the da Vinci telemanipulator system. ITAB 2003: 4Th International IEEE Embs Special Topic Conference on Information Technology Applications in Biomedicine, Conference Proceedings - New Solutions for New Challenges, pp. 326-329.

Dosis A, Bello F, Moorthy K, Munz Y, Gillies D, Darzi A (2004). Real-time synchronization of kinematic and video data for the comprehensive assessment of surgical skills. Newport Beach, Los Angeles, California, Stud Health tech Inform. Medicine Meets Virtual Reality 12 (MMVR). Conference Proceedings, 98: 8288.

Dosis A, Aggarwal R, Bello F, Moorthy K, Munz Y, Gillies D, Darzi A (2005). Sinchronized video and motion analysis for the assessment of procedures in the operating theater. Arch Surg, 140: 293-299.

Draaisma WA, Ruurda JP, Scheffer RCH, Simmermacher RKJ, Gooszen HG, Rijnhart-de Jong HG, Buskens E, Broeders IAMJ (2006). Randomized clinical trial of standard laparoscopic versus robot-assisted Nissen fundoplicationfor gastrooesophageal reflux disease. British J Surg, 93: 1351-1359.

El Nakadi I, Mélot C, Clsset J, DeMoor V, Bétrune K, Feron P, Lingier P, Gelin M (2006). Evaluation of da Vinci Nissen fundoplication clinical results and cost minimization. World J Surg, 30: 1050-1054.

Fabrizio MD, Lee BR, Chan DY, Soianovici D, Jarrett TW, Yang C, Kavoussi LR (2000). Effect of time delay on surgical performance during telesurgical manipulation. J Endourol, 14: 133-138.

Falcone T, Goldberg J, Margossian H, Stevens L (2000) Robotic-assisted laparoscopic microsurgical tubal anastomosis: a human pilot study. Fertil Steril 73: 1040-1042

Falk V, McLoughlin J, Guthart G, Salisbury JK, Walther T, Gummert J, Mohr FW, (1999) Dexterity enhancement in endoscopic surgery by a computercontrolled mechanical wrist. Minim Invasive Therap \& Allied Technol 8: 235242.

Falk V, Mintz D, Grünenfelder J, Fann JI, Burdon TA (2001) Influence of threedimensional vision on surgical telemanipulator performance. Surg Endosc 15: 1282-1288

Galleano R, Carter F, Brown S, Frank T, Cuschieri A(2006). Can armrests improve comfort and task performance in laparoscopic surgery? Ann Surg, 243: 329-333.

Heemskerk J, van Gemert WG, de Vries J, Greve JW, Bouvy ND (2007). Learning curves of robot-assisted laparoscopic surgery compared with conventional laparoscopic surgery an experimental study evaluating skill acquisition of robot-assisted laparoscopic tasks compared with conventional laparoscopic tasks in inexperienced users. Surg Laparosc Endosc Percutan Tech, 17: 171-174.

Hernández J, Bann SD, Munz Y, Moorthy K, Martin S, Dosis A, Bello F, Datta V, 
Rockall T, Darzi A (2004). Qualitative and quantitative analysis of the learning curve of a simulated surgical task on the da Vinci system. Surgical Endoscopy; 18: 372378.

Kano N, Yamakawa T, Ishikawa Y, Miyajima N, Ohtaki S, Kasugai H(1995). Prevention of laparoscopic surgeon's thumb. Surg Endosc, 9: 738-739.

Lee BR, Bishoff JT, Janetschek G, Bunyaratevej P, KamolPronwijit W, Cadeddu JA, Ratchanon S, O'Kelley S, Kavoussi LR (1998). A novel method of surgical instruction international telementoring. World J Urol, 16: 367-370.

Link RE, Bhayani SB, Kavoussi LR (2006). A prospective comparison of robotic and laparoscopic pyeloplasty. Ann Surg, 243: 486-491.

Loulmet D, Carpentier A, d'Attellis N, Berrebi A, Cardon C, Ponzio O, Aupecle B, Relland JYM (1999) Endoscopic coronary artery bypass grafting with the aid of robotic assisted instruments. J Thorac Cardiovasc Surg 118: 4-10.

Marescaux J, Leroy J, Gagner M (2001). Transatlantic robot-assisted telesurgery. Nature; 413: 379-380.

Marescaux J, Leroy J, Rubino F, Smith M, Vix M, Simone M, Mutter D (2002) Transcontinental robot-assisted remote telesurgery: feasibility and potential applications. Ann Surg 235: 487-492

McMahon AJ, Russell AT, Baxter JN, Ross S, Anderson JR, Morran CG, Sunderland G, Galloway D, Ramsey G, O’Dwyer PJ (1994). Laparoscopic versus minilaparotomy cholecystectomy: a randomized trial. Lancet, 343: 135-138.

Mehrabi A, Yetimoglu CL, Nickkholgh A, Kashfi A, Kienle P, Konstantinides L, Ahmadi MR, Fonouni H, Schemmer P, Friess H, Gebhard MM, Buchler MW, Schmidt J, Gutt CN (2006). Development and evaluation of a training module for the clinical introduction of the da Vinci robotic system in visceral and vascular surgery. Surg Endosc, 20: 1376-1382.

Moorthy K, Munz Y, Dosis A, Hernández JD, Martin S, Bello F, Rockall T, Darzi A(2004). Dexterity enhancement with robotic surgery. Surgical Endoscopy, 18: 790-795.

Muhe E (1992). Long-term follow-up after laparoscopic cholecystectomy. Endoscopy, 24: 739-808.

Munz Y, Moorthy K, Kundchadkar R, Hernandez JD, Martin S, Darzi A, Rockall T. Robotic assisted rectopexy. Am J Surg 2003; 187: 88-92.

Munz Y, Dosis A, Lo B, Wang DA, Moorthy K, Pandey V, Stanbridge R, Casula R, Martin S, Bello F, Yang GZ, Darzi A, Rockall T (2003b). Objective assessment of performance of robotic assisted LIMA to LAD anastomosis in a bench-model. Heart Surg Forum 6: S24

Munz Y, Moorthy K, Dosis A, Hernández JD, Bann S, Bello F, Martin S, Darzi A, Rockall $\mathrm{T}$ (2004). The benefits of stereoscopic vision in robotic-assisted performance on bench models. Surgical Endoscopy; 18: 611-616.

National Institutes of Health (1993). National Institutes of Health consensus development conference on gallstones and laparoscopic cholecystectomy. Am J Surg, 165: 390-396.

Obek C, Hubka M, Porter M, Chang L, Porter JR (2005). Robotic versus conventional laparoscopic skills acquisition: implications for training. J Endourol, 19: 1098 1103. 
Okamura AM (2004). Methods for haptic feedback in tele-operated robot assisted surgery. Ind Rob, 31: 499-508.

Ostrosky J, Jacobs M (2003). History of laparoscopy. In: Laparoscopic surgery, CuetoGarcia J, Jacobs M, Gagner M (Ed.), pg 3-4., McGraW-Hill Publishing, ISBN 007-136481-1, New York.

Ramsay CR, Grant A, Wallace SA, Garthwaite PH, Monk AF, Russell IT (2000) Assessment of the learning curve in health technologies. Intl J of Technol Assess Health Care 16: 1095-1108.

Reiley CE (2007). Evaluation of augmented reality alternatives to direct force feedback in robot-assisted surgery: visual force feedback and virtual fixtures. Thesis to the Johns Hopkins University, April 2007. Pp. 134-138.

Ruurda JP, Vroonhoven ThJ, Broeders IA (2002) Robot-assisted surgical systems: a new era in laparoscopic surgery. Ann R Coll Surg Engl 84: 223-226.

Ruurda JP, Draaisma WA, van Hillensberg R, Borel Rinkes IH, Gooszen HG, Janssen LW, Simmermacher RK, Broeders IA (2005). Robot-assisted endoscopic surgery: a four-year single-center experience. Dig Surg, 22: 313-320.

Scott DJ, Young Wn, Tesfay ST, Frawley WH, Rege RV, Jones DB (2001) Laparoscopic skills training. Am J Surg 182: 137-142

Shea JA, Healey MJ, Berlin JA, Clarke JR, Malet PF, Staroscik RN, Schwartz JS, Williams SV (1996) Mortality and complications associated with laparoscopic cholecystectomy. A meta-analysis. Ann Surg 224: 609-620

Smith CD, Farrell TM, McNatt SS, Metrevel RM (2001) Assessing laparoscopic manipulative skills. Am J Surg 181:547-550.

Thompson JM, Ottensmeyer MP, Sheridan TB (1999). Human factors in telesurgery: effects of time delay and asynchrony in video and control feedback with local manipulative assistance. Telemed J, 5: 129-137.

Wang D, Faraci A, Bello F, Darzi A (2006). Simulating tele-manipulator controlled tooltissue interactions using a nonlinear FEM deformable model. Stud Health Technol Inform. 119: 565-567.

Wang D, Bello F, Darzi A (2004). Augmented reality provision in robotically assisted minimally invasive surgery. Proc. of the 18th computer assisted radiology and surgery (CARS). Pp. 527-532.

Wang D, Faraci A, Bello F, Darzi A (2006). Simulating tele-manipulator controlled tooltissue interactions using a nonlinear FEM deformable model. Stud Health Technol Inform. 119: 565-567.

Watson DI, Baigrie RJ, Jamieson GG (1996) A learning curve for laparoscopic fundoplication: Definable, avoidable, or a waste of time? Ann Surg 224: 198-203

Williams LF, Chapman WC, Bonau RA, McGee EC, Boyd RW, Jacobs JK (1993) Comparison of laparoscopic cholecystectomy with open cholecystectomy in a single center. Am J Surg 165: 459-465.

Yu SC, Clapp BL, Lee MJ, Albrecht WC, Scarborough TK, Wilson EB (2006). Robotic assistance provides excellent outcomes during the learning curve for laparoscopic Roux-en-Y gastric bypass: results from 100 robotic-assisted gastric bypass. Am J Surg, 192: 746-749.

Z'graggen K, Wehrli H, Metzger A, Buehler M, Frei E, Klaiber C (1998) Complications of laparoscopic surgery in Switzerland. Surg Endosc 12: 1303-1310. 
Zorn KC, Orvieto MA, Gong Em, Mikhail AA, Gofrit ON, Zagaja GP, Shalhav AL (2007). Robotic radical prostatectomy learning curve of a fellowship-trained laparoscopic surgeon. J Endourol, 21: 441-447. 


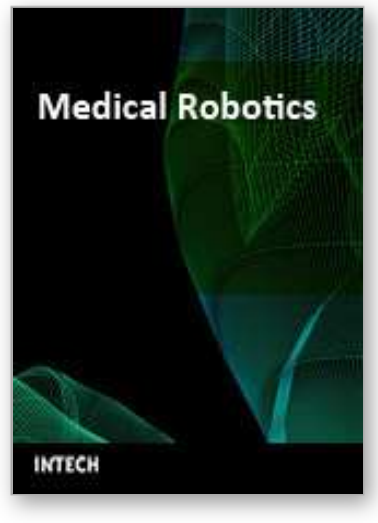

\author{
Medical Robotics \\ Edited by Vanja Bozovic
}

ISBN 978-3-902613-18-9

Hard cover, 526 pages

Publisher I-Tech Education and Publishing

Published online 01, January, 2008

Published in print edition January, 2008

The first generation of surgical robots are already being installed in a number of operating rooms around the world. Robotics is being introduced to medicine because it allows for unprecedented control and precision of surgical instruments in minimally invasive procedures. So far, robots have been used to position an endoscope, perform gallbladder surgery and correct gastroesophogeal reflux and heartburn. The ultimate goal of the robotic surgery field is to design a robot that can be used to perform closed-chest, beating-heart surgery. The use of robotics in surgery will expand over the next decades without any doubt. Minimally Invasive Surgery (MIS) is a revolutionary approach in surgery. In MIS, the operation is performed with instruments and viewing equipment inserted into the body through small incisions created by the surgeon, in contrast to open surgery with large incisions. This minimizes surgical trauma and damage to healthy tissue, resulting in shorter patient recovery time. The aim of this book is to provide an overview of the state-of-art, to present new ideas, original results and practical experiences in this expanding area. Nevertheless, many chapters in the book concern advanced research on this growing area. The book provides critical analysis of clinical trials, assessment of the benefits and risks of the application of these technologies. This book is certainly a small sample of the research activity on Medical Robotics going on around the globe as you read it, but it surely covers a good deal of what has been done in the field recently, and as such it works as a valuable source for researchers interested in the involved subjects, whether they are currently "medical roboticists" or not.

\title{
How to reference
}

In order to correctly reference this scholarly work, feel free to copy and paste the following:

Juan D. Hernandez R., Fernando Bello and Ara Darzi (2008). Surgical Skills Training For Robotic Assisted Surgery, Medical Robotics, Vanja Bozovic (Ed.), ISBN: 978-3-902613-18-9, InTech, Available from: http://www.intechopen.com/books/medical_robotics/surgical_skills_training_for_robotic_assisted_surgery

\section{INTECH}

open science | open minds

\section{InTech Europe}

University Campus STeP Ri

Slavka Krautzeka 83/A

51000 Rijeka, Croatia

Phone: +385 (51) 770447

\section{InTech China}

Unit 405, Office Block, Hotel Equatorial Shanghai

No.65, Yan An Road (West), Shanghai, 200040, China

中国上海市延安西路65号上海国际贵都大饭店办公楼 405 单元

Phone: +86-21-62489820 
Fax: +385 (51) 686166

Fax: +86-21-62489821

www.intechopen.com 
(C) 2008 The Author(s). Licensee IntechOpen. This chapter is distributed under the terms of the Creative Commons Attribution-NonCommercialShareAlike-3.0 License, which permits use, distribution and reproduction for non-commercial purposes, provided the original is properly cited and derivative works building on this content are distributed under the same license. 